\title{
VENTAJAS DEL PROCESO DE REFORESTACIÓN SOBRE LA ATENUACIÓN DE LA EROSIÓN Y PROPUESTA DE PROTECCIÓN Y DESARROLLO DE UN ÁREA DE RECARGA EN EL VALLE CENTRAL DE COSTA RICA.
}

\author{
Asdrúbal Vargas S. \\ Escuela Centroamericana de Geología, Apdo 35-2060. \\ Universidad de Costa Rica, San José, Costa Rica.
}

(Recibido 5/11/1997; Aceptado 3/12/1997)

\begin{abstract}
The results of the study demostrate the reduction of erosion and run-off events in forested areas compared to zones of agricultural use (grassland) in the subbasins of the River Durazno and the upper part of the River Virilla, which are considered recharge areas of the deep aquifers for the Central Valley of Costa Rica. Four areas of environmental protection are proposed in this study: 1) the protection of riparian zone, 2) the protection of springs, 3 ) the planing of agricultural use and 4) the development of comercial forestation.

RESUMEN: Por medio de coeficientes de escorrentía, infiltración y balances hídricos, se demuestra la ventaja cuantitativa del proceso de reforestación en comparación con el uso agrícola en cuanto a la disminución de la erosión y de los eventos de escorrentía en las subcuencas del Río Durazno y la parte alta del Río Virilla, consideradas áreas de recarga para acuíferos profundos del Valle Central de Costa Rica.

Se proponen cuatro áreas de manejo ambiental: 1) protección de cauces y captaciones superficiales, 2) protección de manantiales, 3) uso agrícola o residencial, 4) uso ganadero y plantación forestal comercial.
\end{abstract}

\section{INTRODUCCIÓN}

Debido a la importancia del recurso hídrico en la generación de energía eléctrica y en vista de la contaminación de las aguas del Río Virilla varias instituciones, entre ellas la Compañía Nacional de Fuerza y Luz (CNFL), están llevando a cabo un Plan de Mejoramiento Ambiental de la parte alta del río Virilla (PLAMA VIRILLA). Dentro de este proyecto se tiene contemplado un programa de reforestación que incluye la protección de nacientes y de las áreas de recarga.

Con este trabajo se pretende medir la escorrentía y la recarga a los acuíferos que sucede en un área de repasto y en una plantación forestal y evaluar por medio de balances hídricos la efectividad del proceso de reforestación sobre la atenuación de la erosión. Además se contempla la definición de áreas de protección ambiental.

La zona de estudio se ubica al NE de la Depresión Intermontana Central (Valle Central) de Costa Rica en la falda NW del Macizo Volcánico Irazú y comprende las subcuencas hidrográficas en la parte alta del Río Virilla y Río Durazno, definidas hasta su confluencia y comprendidas en las hojas topográficas Abra \# 3345 I e Istarú 3445 IV (Fig. 1).

La geología del área está compuesta por cenizas, lahares, lavas y brechas, coluvios y aluviones, considerándose los aluviones los materiales de mayor almacenamiento y transmisión de agua.

El Río Virilla y sus afluentes, la Quebrada Varela, Quebrada Sangrino y la Quebrada 

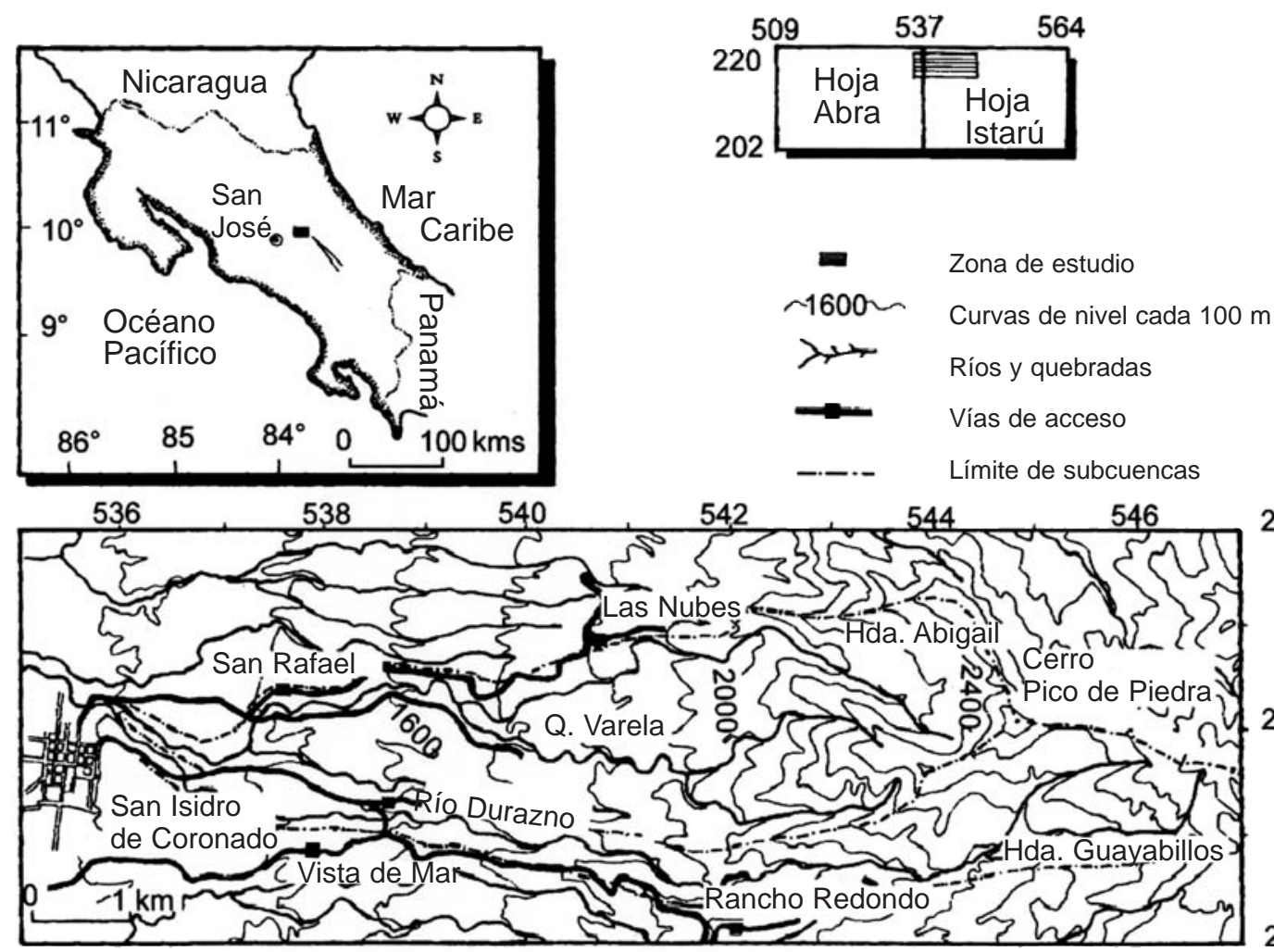

220

Fig. 1: Ubicación del área de estudio.

Montelindo, forman el sistema hidrográfico de la subcuenca del Río Virilla, mientras que el Río Durazno, junto con afluentes de orden 1, principalmente, constituyen el sistema de la subcuenca del río Durazno.

La precipitación promedio anual alcanza los $2000 \mathrm{~mm}$ y la temperatura promedio es de $16,7^{\circ} \mathrm{C}$. El clima se clasifica como húmedo templado (GÓMEZ, 1985).

Las pendientes del terreno varían desde muy altas hasta bajas (VARGAS, 1994). Una gran sección de terreno en las unidades de pendiente muy alta, alta y moderada se utilizan para uso pastoril.

\section{USO DEL SUELO}

El suelo en las subcuencas es usado para uso residencial, comercial e industrial (cuadro 1).

El uso pastoril abarca 4,5 y $5,8 \mathrm{~km}^{2}$ del área de las subcuencas respectivamente, para un total de $10,3 \mathrm{~km}^{2}$, siendo el uso del suelo que ma- yor extensión ocupa.

El suelo se utiliza además para sustentar bosque primario y secundario, plantaciones forestales, viveros de plantas ornamentales y la plantación de hortalizas.

\section{ASPECTOS HIDROLÓGICOS}

El Instituto Costarricense de Acueductos y Alcantarillados (AyA) ha realizado mediciones mensuales del caudal del río Virilla y del río Durazno entre los años 1985 a 1992. De los valores medidos en un mes determinado se ha extraído el promedio aritmético, presentándose tales valores de manera gráfica en la figura 2.

Los caudales promedio obtenidos representan de manera aproximada las variaciones mensuales solo en el caso del río Durazno, donde los caudales más bajos ocurren en febrero, abril y mayo, producto de la estación seca y los caudales mayores ocurren en setiembre y octubre en correspondencia con la estación lluviosa. Por 
CUADRO 1

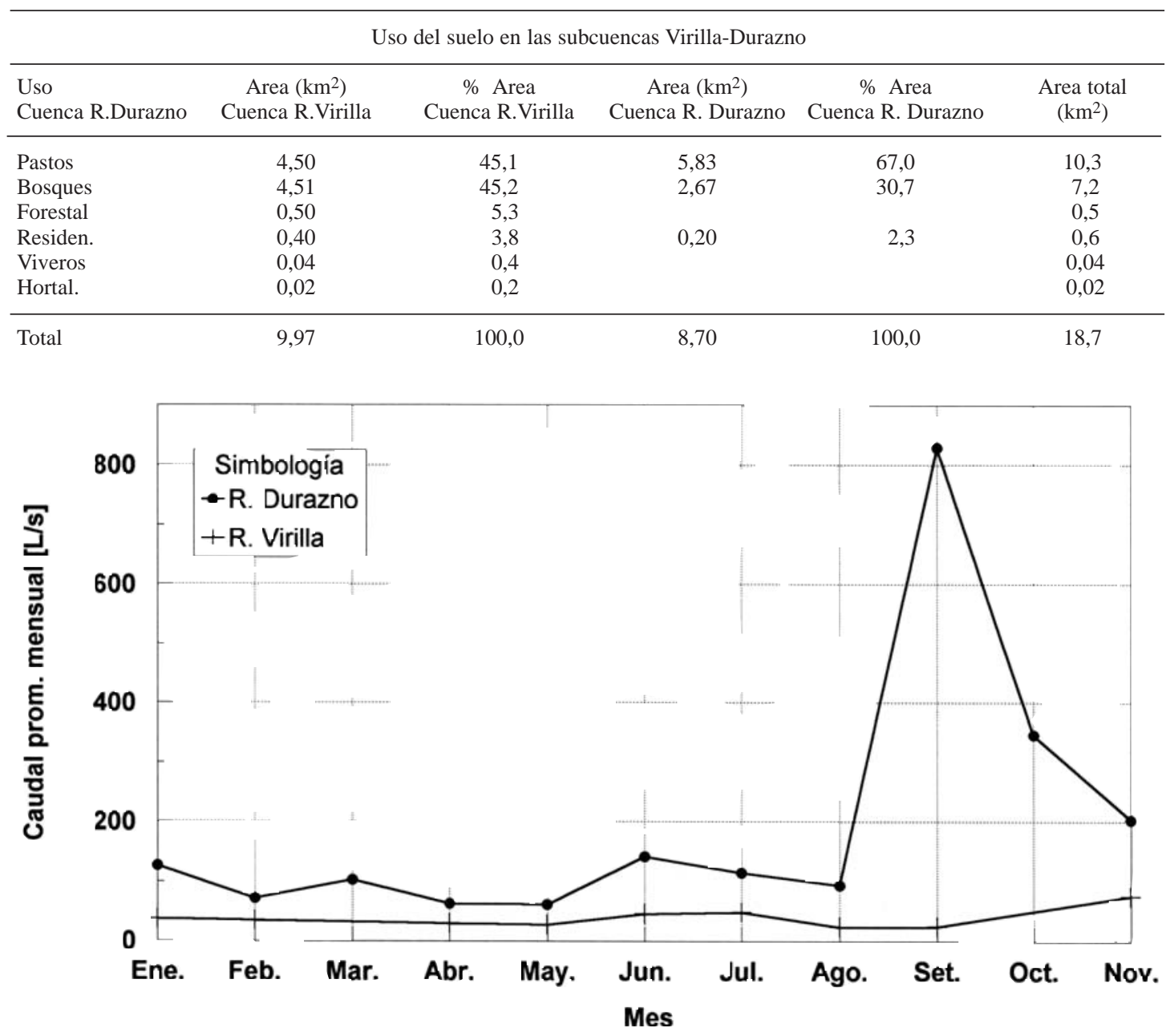

Fig. 2: Hidrograma de los ríos Virilla y Durazno.

su parte, los caudales promedio obtenidos para el río Virilla no representan las variaciones climáticas, tanto por la falta de datos como por mediciones realizadas en días donde no existían las condiciones climáticas generales, como por ejemplo en veranillos.

\section{ESCORRENTIA SUPERFICIAL E INFILTRACIÓN}

Cuando la precipitación llega a la superficie del suelo, dependiendo de su intensidad, de la textura del suelo, del nivel de compactación y de la humedad, el agua puede infiltrarse o escurrir hasta alcanzar un río o quebrada. El agua infiltrada en el subsuelo puede ser evapotranspirada, correr como flujo subsuperficial o recargar acuíferos. Sin embargo los factores que condicionan la escorrentía o la eventual recarga a los acuíferos están influenciados en gran medida por el uso del suelo. Es así como se han efectuado cálculos de los coeficientes de escorrentía e infiltración tomando en cuenta un terreno dedicado a la explotación ganadera, ubicada en las coordenadas Lambert, 217,0-542,5 de la Hoja Topográfica Istarú, y un terreno aledaño dedicado a la plantación forestal, con una edad aproximada de 5 
años, ubicado en las coordenadas Lambert 217,4-542,5.

Para el cálculo de los coeficientes de escorrentía (Ce, adimensional) e infiltración (Cf, adimensional) se utilizó la expresión derivada de LIRIOS (1980); y modificada por LOSILLA et. al (1992):

$$
\begin{aligned}
& \mathrm{Ce}=\mathrm{I}_{24} / \mathrm{Fc} * 24 \\
& \mathrm{Cf}=1-\mathrm{Ce}=1-\mathrm{I}_{24} / \mathrm{Fc} * 24
\end{aligned}
$$

donde:

$\mathbf{I}_{\mathbf{2 4}}$ : es el promedio de la intensidad máxima en 24 horas expresado en $\mathrm{mm} / \mathrm{hr}$. En este caso se ha usado los valores de intensidad de la Estación Pluviométrica Rancho Redondo, para los años 1987-1991.

Fc: es la capacidad de infiltración determinada por el método del doble anillo expresada en $\mathrm{mm} / \mathrm{hr}$., estimándose para un repasto seleccionado $(10,2 \mathrm{~mm} / \mathrm{hr}$.) y una plantación forestal $(173,8$ $\mathrm{mm} / \mathrm{hr}$.). Se realizaron tres pruebas en el repasto y tres pruebas en la plantación forestal, asumiéndose representativas y generalizándose a las subcuencas con las reservas del caso. Es necesario considerar que durante las pruebas en la plantación forestal no se removió la materia orgánica acumulada en la superficie, lo cual favorece el flujo subsuperficial que posiblemente terminará infiltrándose en algún momento. Además se debe tomar en cuenta que el suelo en el área de repasto ha sido compactado por el transitar del ganado.

El cuadro 2 contiene el promedio mensual de la intensidad máxima de la precipitación, los coeficientes de escorrentía e infiltración para los repastos seleccionados y la plantación forestal. Se nota que los coeficientes de escorrentía en el repasto son mayores en todos los meses, que los correspondientes a la plantación forestal, mientras que los coeficientes de infiltración más bajos ocurren en los repastos seleccionados.

Tomando en cuenta la precipitación promedio mensual, el área de repastos, el área de bosques y los coeficientes de escorrentía, se ha calculado la escorrentía superficial mensual en $\mathrm{m}^{3} /$ ha para pastos y para una plantación forestal. La máxima escorrentía en el área de pastos y la plantación forestal ocurre en el mes de octubre con un valor de $1098,8 \mathrm{~m}^{3} / \mathrm{ha}$ y de $64,4 \mathrm{~m}^{3} / \mathrm{ha}$, respectivamente, mientras que durante el mes de marzo se presenta la menor escorrentía, 3,48 $\mathrm{m}^{3} /$ ha y $0,21 \mathrm{~m}^{3} /$ ha, respectivamente (Fig.3).
CUADRO 2

Coeficientes de escorrentía e infiltración estimados para las subcuencas Virilla-Durazno

\begin{tabular}{lccccc}
\hline Mes & $\begin{array}{c}\text { Intensidad } \\
\text { máx } \\
\text { promedio } \\
24 \mathrm{hrs} \\
(\mathrm{mm})\end{array}$ & $\begin{array}{c}\mathrm{Ce} \\
\text { Pastos } \\
\mathrm{Fc}=10.2 \\
\mathrm{~mm} / \mathrm{hr} .\end{array}$ & $\begin{array}{c}\mathrm{Ce} \\
\text { Forestal } \\
\mathrm{Fc}=173,8 \\
\mathrm{~mm} / \mathrm{hr}\end{array}$ & $\begin{array}{c}\mathrm{Cf} \\
\text { Pastos }\end{array}$ & $\begin{array}{c}\text { Cf } \\
\text { Forestal }\end{array}$ \\
\hline Ene. & 16,4 & 0,067 & 0,0039 & 0,933 & 0,996 \\
Feb. & 4,2 & 0,017 & 0,0010 & 0,983 & 0,999 \\
Mar. & 3,7 & 0,015 & 0,0009 & 0,985 & 0,999 \\
Abr. & 14,3 & 0,058 & 0,0034 & 0,942 & 0,997 \\
May. & 41,2 & 0,170 & 0,0099 & 0,830 & 0,990 \\
Jun. & 51,6 & 0,210 & 0,012 & 0,790 & 0,988 \\
Jul. & 44,9 & 0,180 & 0,011 & 0,820 & 0,989 \\
Ago. & 63,0 & 0,260 & 0,015 & 0,740 & 0,985 \\
Set. & 72,2 & 0,290 & 0,017 & 0,710 & 0,983 \\
Oct. & 72,3 & 0,290 & 0,017 & 0,710 & 0,983 \\
Nov. & 31,8 & 0,130 & 0,0076 & 0,870 & 0,990 \\
Dic. & 29,6 & 0,120 & 0,0071 & 0,88 & 0,993 \\
\hline
\end{tabular}

Un cambio paulatino del uso del suelo, hacia la reforestación disminuiría la escorrentía superficial, disminuyendo la erosión de los suelos y el aporte de materiales terrígenos a los ríos y quebradas.

A partir de los valores de escorrentía superficial mensual en $\mathrm{m}^{3} / \mathrm{ha}$ obtenidos para el área de repasto y de la plantación forestal se aprecian cinco períodos de escorrentía superficial bien definidos en la curva de escorrentía en repasto.

Período 1: consta de cuatro meses, de enero a abril con los valores menores para ambas curvas, donde no sobrepasan los $40 \mathrm{~m}^{3} / \mathrm{ha}$.

Período 2: consta de dos meses, mayo y junio, con una tendencia creciente.

Período 3: se presenta en julio, con un decrecimiento de la escorrentía, quizá asociado al veranillo climático del Valle Central.

Período 4: ocupa los meses de agosto, setiembre y octubre con la característica, de que se alcanzan los valores mayores de escorrentía superficial (1098 $\mathrm{m}^{3} /$ ha en octubre).

Período 5: se caracteriza este lapso de tiempo por la disminución paulatina de la escorrentía, en los meses de noviembre y diciembre.

Partiendo de estos períodos establecidos, no es recomendable, la apertura de caminos, el movimiento de materiales y el pastoreo intensivo 


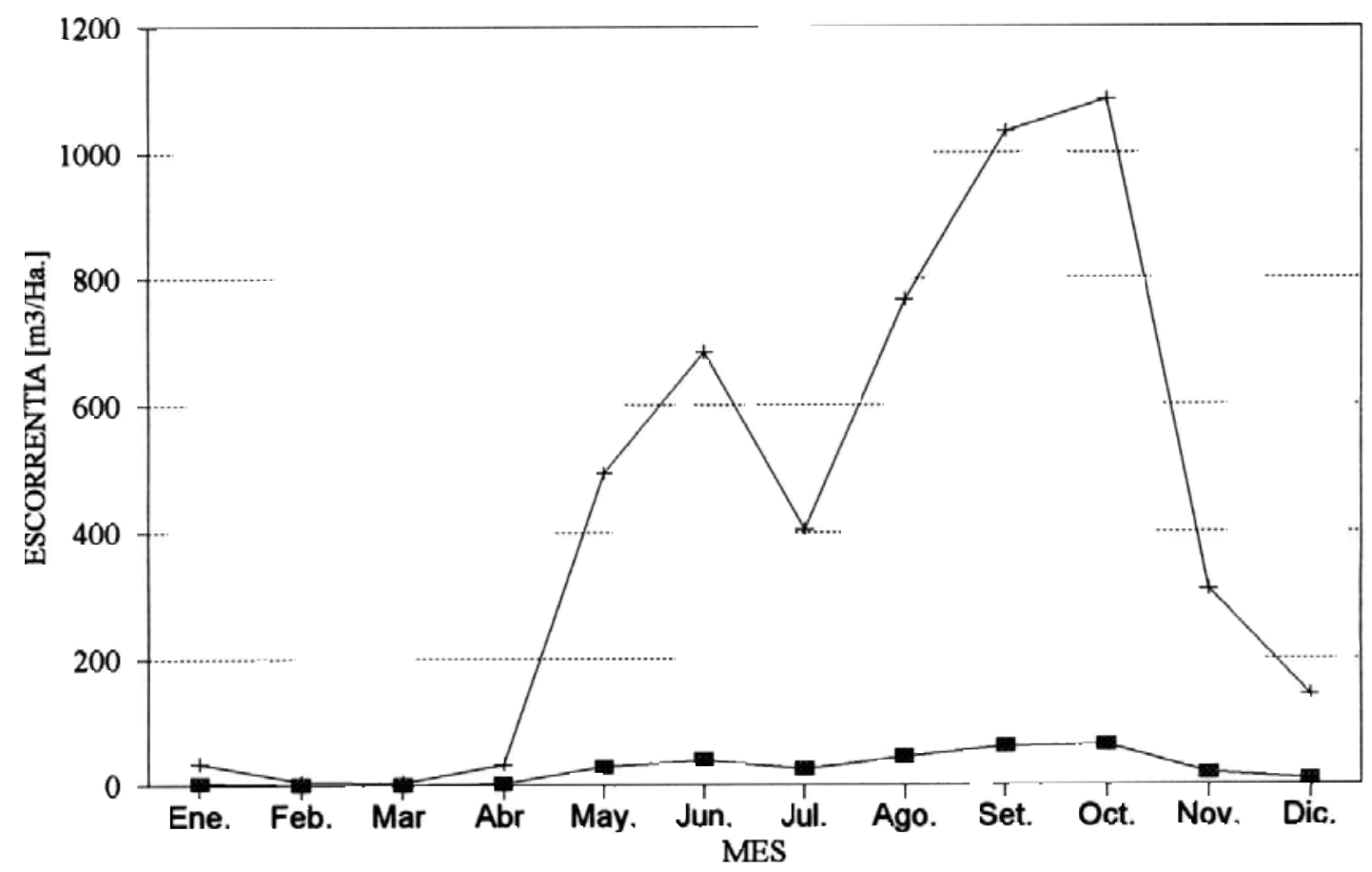

\section{$\rightarrow$ ESCOR. REPASTO $\rightarrow$ ESCOR. PLAN. FORES.}

Fig. 3: Variación de la escorrentía superficial en los repastos y en una plantación forestal.

en los períodos 2,4 y 5 , ya que se favorece la erosión y la depositación de materiales en los ríos y quebradas. Cabe observar, para la curva de escorrentía en la plantación forestal la tendencia casi uniforme, lo que implica la atenuación de la escorrentía aún en los meses de alta pluviosidad, esto debido a alta evapotranspiración y a una mayor capacidad de infiltración.

\section{BALANCE HíDRICO}

A partir del balance hídrico de suelos es posible realizar una evaluación cuantitativa de los recursos de agua y sus modificaciones por la influencia del uso del suelo. El balance hídrico se basa en la aplicación del principio de conservación de masas, expresadas como precipitación, intercepción, evapotranspiración y recarga potencial, entre otros.

La recarga potencial estimada se ha graficado en la figura 4 , notándose que la recarga al acuífero sucede solo en los repastos desde el mes de abril hasta diciembre. Esto ocurre debido a que la evapotranspiración potencial es menor para el área de repasto disponiéndose así de una cierta cantidad de agua que puede ser recargada al acuífero.

Las figuras 5 y 6 presentan de manera gráfica los valores obtenidos de los balances hídricos en el área de repasto y la plantación forestal para la precipitación, la intercepción, la recarga potencial, la evapotranspiración potencial y la escorrentía superficial.

Se nota en la figura 5 del balance hídrico obtenido para el área de repastos, la relación de los puntos de inflexión mayores de la escorrentía superficial y la recarga potencial al acuífero con la precipitación, mientras tanto la evapotranspiración y la intercepción muestran una tendencia constante.

Por su parte del balance hídrico para la plantación forestal (Fig. 6) se desprende que la recarga potencial durante el año es nula debido a 

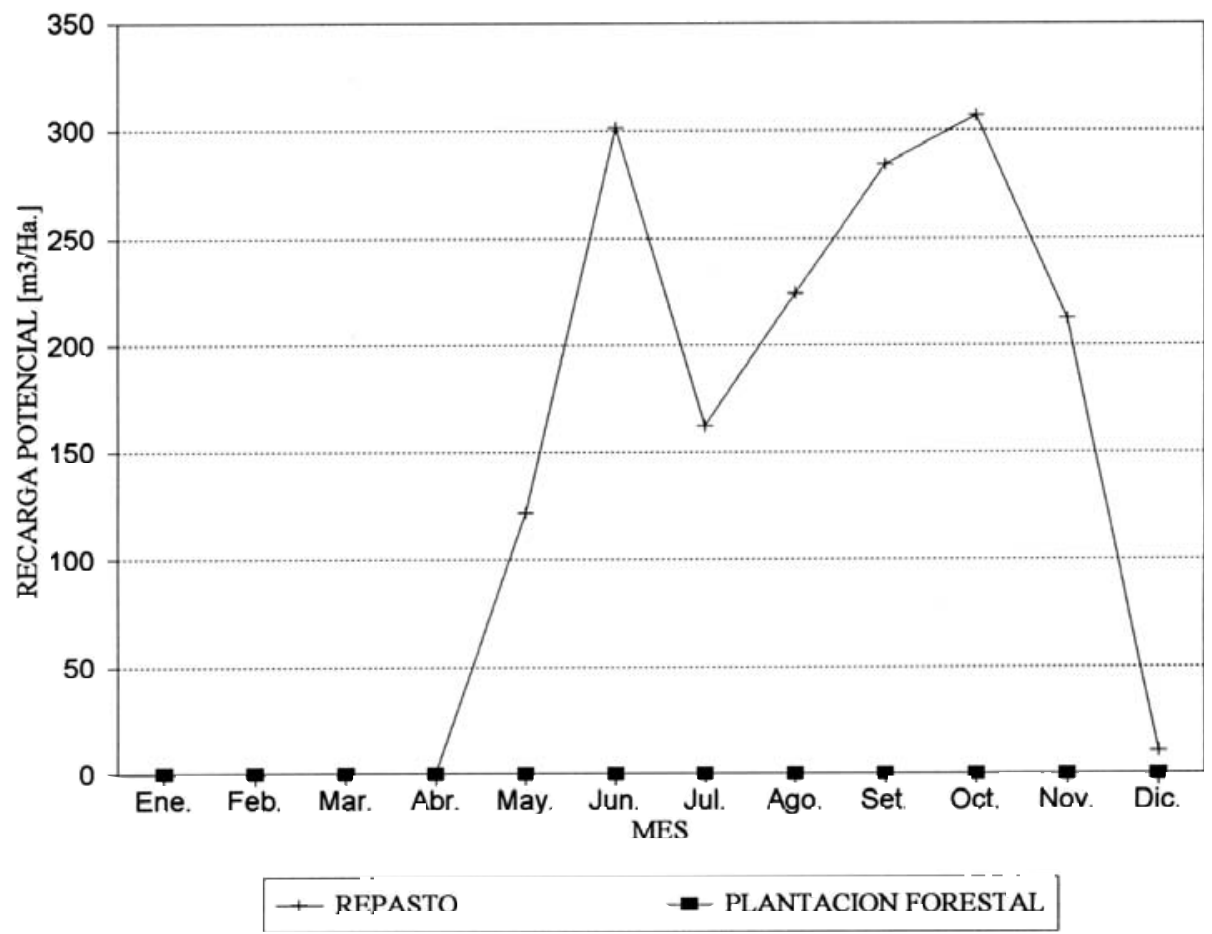

Fig.4: Variación de la recarga en los repastos y en la plantación forestal.
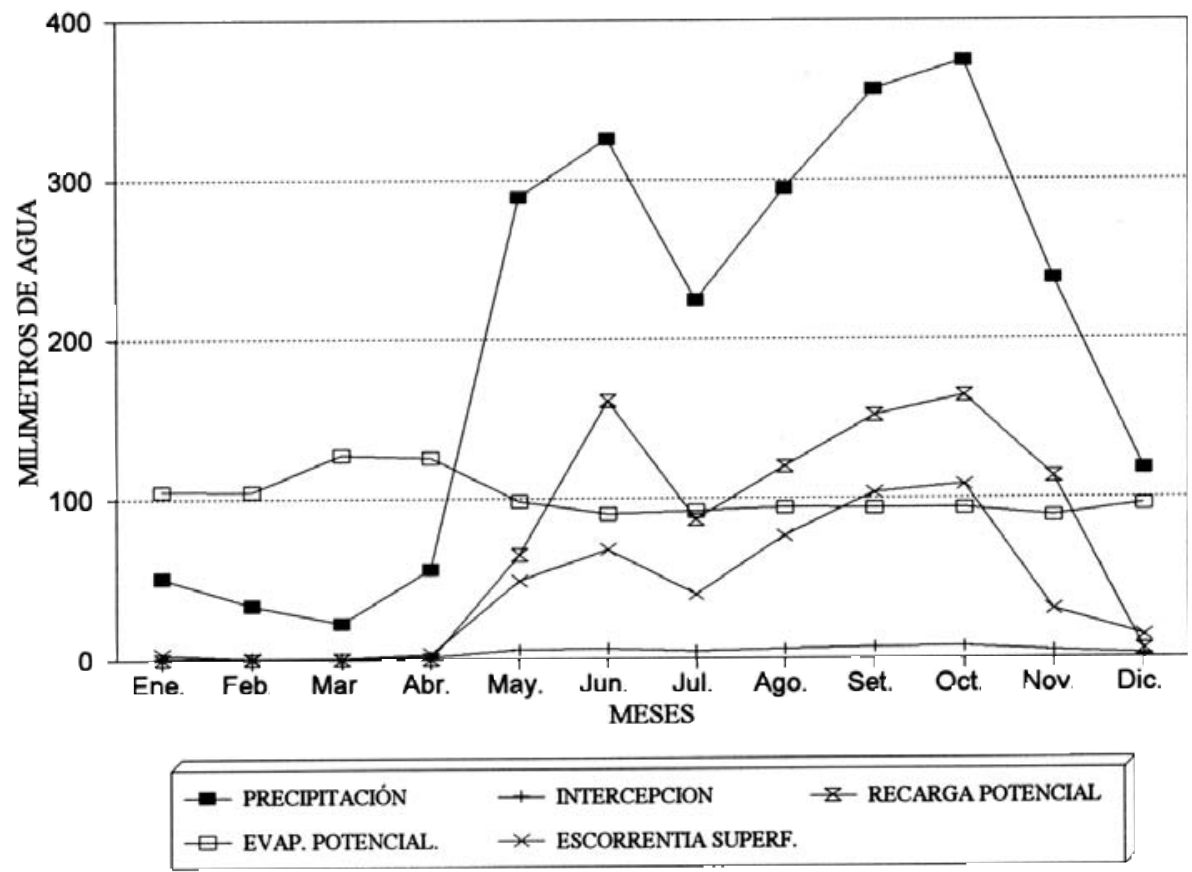

Fig. 5: Balance hídrico para repastos. 


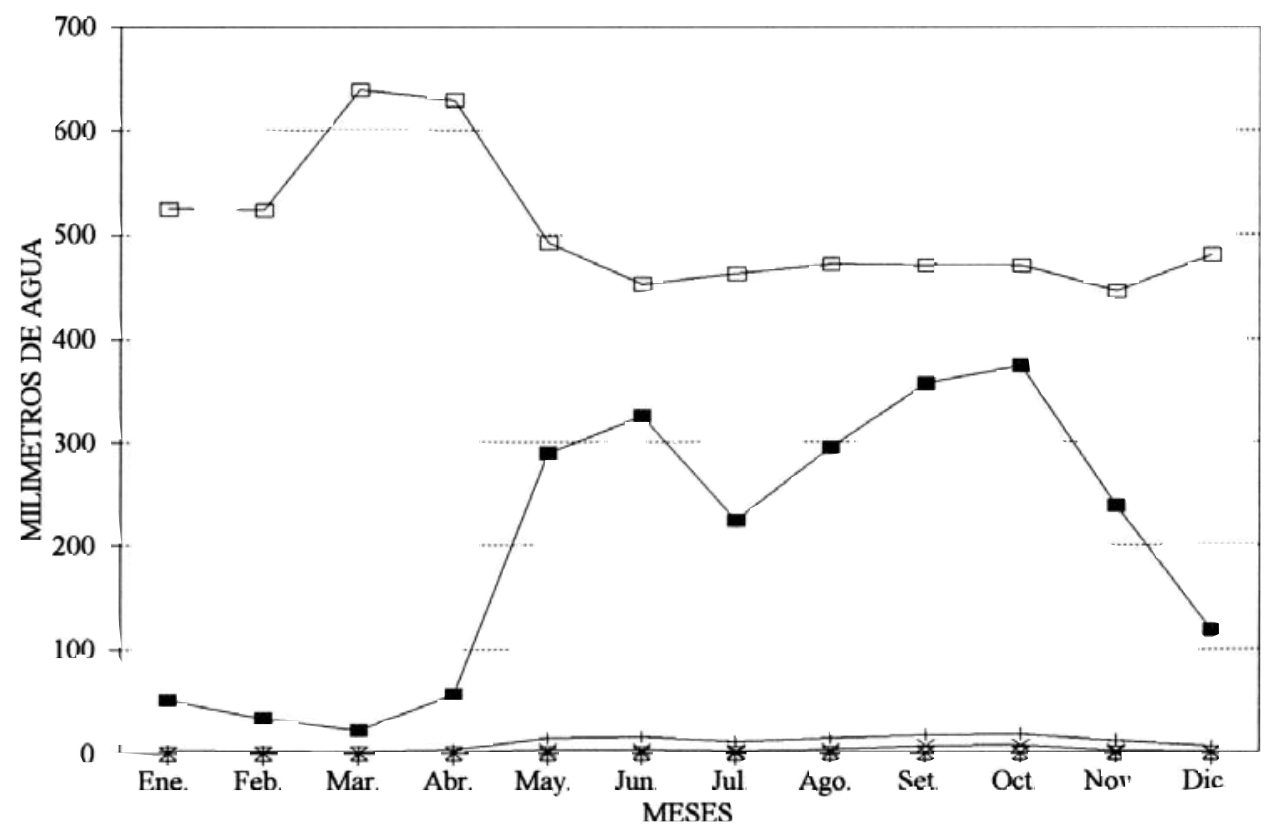

$\begin{array}{ll}- \text { - PRECIPITACION } & + \text { INTERCEPCION } \\ \square \text { EVAPTRANS. POT. } & \neq \text { ESCORRENTIA SUPERF. }\end{array}$

Fig. 6: Balance hídrico para plantación forestal.

que la evapotranspitración potencial supera los valores de la precipitación. Según HARGRAVES (comunicación personal) la evapotranspiración en un bosque puede alcanzar en el área centroamericana un valor 15 veces mayor que en un cultivo tradicional. En este trabajo se emplea un valor de uso consuntivo de 5, pues la plantación forestal presenta un nivel de desarrollo intermedio. La escorrentía superficial se mantiene al igual que la intercepción relativamente constante. Este gráfico demuestra la efectividad del proceso de reforestación al atenuar la escorrentía superficial y con esto la erosión de suelos.

\section{LINEAMIENTOS PARA LA PROTECCIÓN DEL RECURSO HÍDRICO EN LAS SUBCUENCAS VIRILLA-DURAZNO}

Considerando la geomorfología, el uso actual del suelo, las captaciones de agua superficial y subterránea, la ubicación de los manantiales y la recarga a acuíferos, los cuales están detallados en VARGAS, 1994) se proponen las siguientes áreas de protección.

\section{Protección de cauces y captaciones superficiales}

Se ha establecido a lo largo del Río Virilla, Quebrada Sangrino, Quebrada Varela, Quebrada Fanguillo, Quebrada Montelindo y Río Durazno. Ocupa un área de $0,7 \mathrm{~km}^{2}$, es decir un 3,9\% del área total. La protección de los cauces y captaciones superficiales es fundamental para mantener la buena calidad del agua, evitando la erosión y disposición de materiales terrígenos así como la entrada de animales al curso de agua, asegurando un suministro de agua en buen estado.

En Costa Rica, la normativa de protección está basada en la Ley Forestal No 7174 (28 de junio de 1990), la cual declara zona protectora, una zona mínima de diez metros a ambos lados en la ribera de todos los ríos, quebradas o arroyos, permanentes o no, si el terreno es plano, y de cincuenta metros horizontales si el terreno es quebrado. 
Para complementar dichas disposiciones legales se recomienda llevar a cabo las regulaciones propuestas en el cuadro 3.

\section{Protección de manantiales}

El área establecida para la protección de manantiales se caracteriza por fuertes pendientes y un uso del suelo pastoril. Ocuparía $13,7 \mathrm{~km}^{2}$, lo que representaría un $72,7 \%$.

La Ley Forestal No 7174 (28 de junio de 1990) en el artículo 68, inciso 1, declara zona protectora las áreas que se encuentren bordeando los manantiales que nacen en los cerros, en un radio de doscientos metros y de cien metros si los manantiales nacen en terrenos planos, sin embargo el área de recarga de un manantial no esta restringida a los doscientos metros, por lo tanto se propone ampliar el área de protección como se muestra en el mapa de elementos hidrogeológicos y área de protección (Fig. 7). Las restricciones pertinentes para esta unidad, se describen en el cuadro 4.

La protección de manantiales y sus áreas de recarga se basa en la reforestación. Sin embargo en la realidad la ejecución de dicho proceso está sometido a presiones económicas muy fuertes. Por lo tanto el diseño de planes

\section{CUADRO 3}

Regulación de actividades para la protección de cauces y captaciones superficiales en las subcuencas Virilla-Durazno

\begin{tabular}{lc}
\hline \multicolumn{1}{c}{ TIPO DE ACTIVIDAD } & $\begin{array}{c}\text { ZONA DE } \\
\text { PROTECCION } \\
\text { INMEDIATA }\end{array}$ \\
\hline Construcción de urbanizaciones & No se permite \\
$\begin{array}{l}\text { Descarga de aguas negras } \\
\text { Descarga de aguas pluviales de casa y } \\
\text { urbanizaciones. }\end{array}$ & No se permite \\
$\begin{array}{l}\text { Productos fertilizantes } \\
\text { Descarga de efluentes líquidos } \\
\text { agropecuarios (lecherías y porquerizas) }\end{array}$ & No se permite \\
$\begin{array}{l}\text { Desechos domésticos individuales } \\
\text { Extracción de materiales de cauces }\end{array}$ & No se permite \\
$\begin{array}{l}\text { Acceso de ganado a ríos y quebradas } \\
\text { Invernaderos de flores ornamentales }\end{array}$ & No se permite \\
y frutales & No se permite \\
Vertido de aguas con agroquímicos & No se permite \\
Construcción de caminos & No se permite \\
& \\
\hline
\end{tabular}

de manejo integrado en áreas particulares con la participación de propietarios, municipios y el PLAMA VIRILLA se hace necesario.

\section{Uso agrícola o residencial}

Se localiza en las partes bajas de las subcuencas. Ocuparía $0,7 \mathrm{~km}^{2}$ lo que representa $3,6 \%$. Se caracteriza por pendientes bajas y un desarrollo urbanístico incipiente. Para disminuir la contaminación de aguas superficiales o subterráneas se proponen las restricciones del cuadro 5.

\section{Uso ganadero y plantación forestal comercial}

Ocuparía 3,7 km² del área en las subcuencas, lo que representa $19,7 \%$. Su ubicación concuerda con la Lechería Santa Teresita, Finca Cabaña, Hacienda San Miguel y Hacienda Guayabillos. La disposición de hatos de ganado de leche en concomitancia con plantaciones forestales de tipo comercial es recomendable en un área de pendiente moderada, elementos hidrogeológicos de explotación de agua y presiones urbanísticas incipientes.

En esta área sería posible, a diferencia de la unidad de protección de manantiales, la explotación maderera, ya que la apertura de caminos y la creación de espacios abiertos no incidirían en gran medida sobre el recurso hídrico. Las restricciones

\section{CUADRO 4}

Regulación de actividades para la protección de manantiales en las subcuencas Virilla- Durazno

\begin{tabular}{|c|c|}
\hline TIPO DE ACTIVIDAD & $\begin{array}{l}\text { ZONA DE } \\
\text { PROTECCION } \\
\text { INMEDIATA }\end{array}$ \\
\hline Construcción de urbanizaciones & No se permite \\
\hline Descarga de aguas negras & No se permite \\
\hline $\begin{array}{l}\text { Descarga de aguas pluviales de casas } \\
\text { y urbanizaciones }\end{array}$ & No se permite \\
\hline Productos fertilizantes & No se permite \\
\hline $\begin{array}{l}\text { Descarga de efluentes líquidos } \\
\text { agropecuarios (lecherías y porquerizas) }\end{array}$ & No se permite \\
\hline Desechos domésticos individuales & No se permite \\
\hline $\begin{array}{l}\text { Invernaderos de flores ornamentales } \\
\text { y frutales }\end{array}$ & No se permite \\
\hline Vertido de aguas con agroquímicos & No se permite \\
\hline Construcción de caminos & $\begin{array}{l}\text { construirse nuevos } \\
\text { s existentes deben } \\
\text { lastre suelto, cons- } \\
\text { s y alcantarillados }\end{array}$ \\
\hline
\end{tabular}



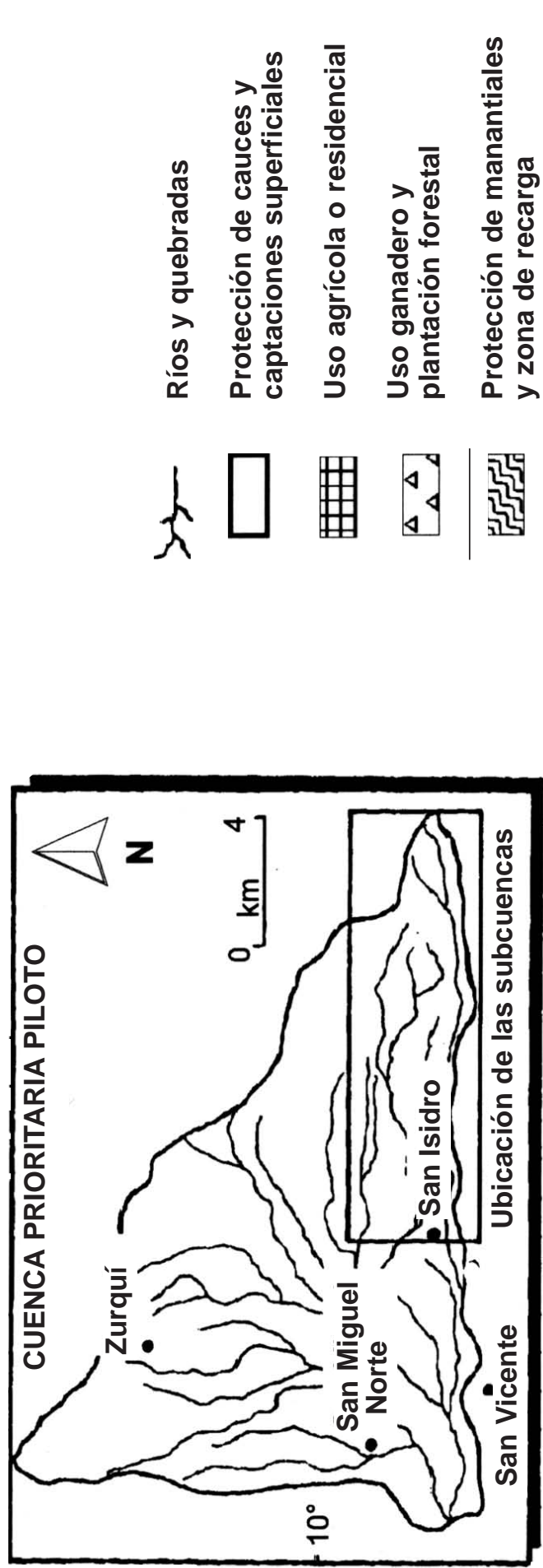

$\frac{\infty}{\pi}$

$\stackrel{\sim}{i}$

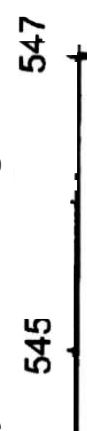

-
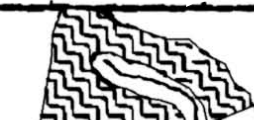

in

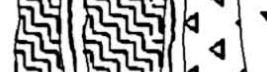

in

4

42540

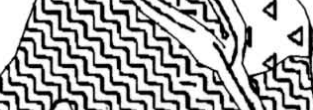

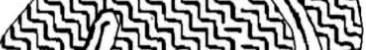

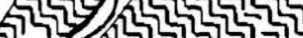

证。

(4)

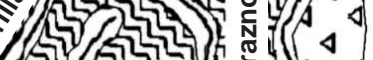

พั้

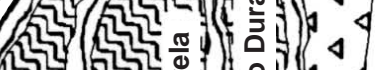
(2)

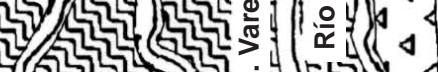

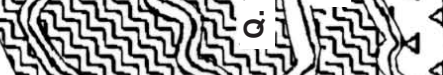

(4)

2

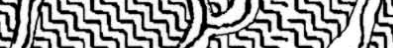

䓃

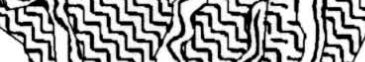

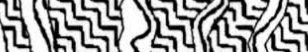

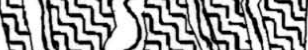

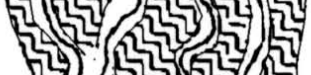

24).

हై

$\left.\left.\int\left\{\begin{array}{lll}4 & 4 & 4 \\ 4 & 4 & 4\end{array}\right\}<\right\}<\right\}$

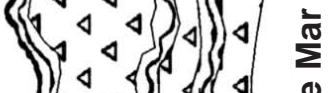

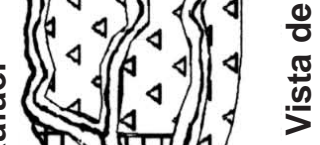

กิก

๓ి.

ติ

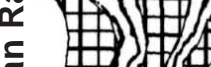

๗ิ 
CUADRO 5

Regulación de actividades para uso agrícola o residencial en las subcuencas Virilla-Durazno

\begin{tabular}{cc}
\hline TIPO DE ACTIVIDAD & SUBCUENCAS \\
VIRILLA-DURAZNO
\end{tabular}

Construcción de urbanizaciones

Descarga de aguas negras

\section{Aplicación de productos}

fertilizantes

Descarga de efluentes líquidos agropecuarios (lecherías y porquerizas)

Desechos domésticos individuales

Extracción de materiales de cauces

Acceso de ganado a ríos y quebradas

Invernaderos de flores ornamentales y frutales

Vertido de aguas con agroquímicos

Construcción de caminos

necesarias en la zona de uso ganadero y plantación forestal para proteger el recurso hídrico, de la contaminación se describen en el cuadro 6 .

\section{CONCLUSIONES}

Los coeficientes de escorrentía mensuales para el repasto son mayores que los correspondientes a la plantación forestal, ya que el uso pastoril modifica la textura del suelo. Es así como la

\section{CUADRO 6}

Regulación de actividades ganaderas y plantación forestal comercial en las subcuencas Virilla- Durazno

\begin{tabular}{ll}
\hline TIPO DE ACTIVIDAD & \multicolumn{1}{c}{$\begin{array}{c}\text { SUBCUENCAS } \\
\text { VIRILLA-DURAZNO }\end{array}$} \\
\hline $\begin{array}{l}\text { Utilización de productos } \\
\text { fertilizantes. }\end{array}$ & $\begin{array}{l}\text { Solo con ingredientes y dosis } \\
\text { aprobados por el M.S., y de } \\
\text { aplicación manual. }\end{array}$
\end{tabular}

Descargo de efluentes líquidos agropecuarios (lecherías y porquerizas)

Solo con tratamiento aprobado por el Ministerio de salud.

Acceso de ganado a ríos y quebradas

No se permite. Deben construirse abrevaderos a $50 \mathrm{~m}$ de las márgenes

Invernaderos de flores ornamentales y frutales

Sólo en máximo de 5\% del área no mayores a $2000 \mathrm{~m}^{2}$, y la lluvia interceptada dispuesta en zanjas de infiltración.

Vertido de aguas con agroquímicos

Deben ser tratadas en plantas de tratamiento.

Construcción de caminos

No deben construirse nuevos caminos; los existentes deben cubrirse con lastre suelto, construir cunetas y alcantarillas de infiltración y no ampliar su ancho.

escorrentía superficial en repastos adquiere fluctuaciones dependientes de las lluvias, contrario al comportamiento estable y con valores muy bajos de la escorrentía en la plantación forestal.

Partiendo de los períodos de escorrentía críticos establecidos, no es recomendable la apertura de caminos, el movimiento de materiales y el pastoreo intensivo de abril a junio y de julio a diciembre ya que se favorece la erosión y la depositación de materiales en los ríos y quebradas.

Por su parte los coeficientes de infiltración mensuales para la plantación forestal superan los coeficientes de infiltración mensuales para los repastos seleccionados. Esto sucede por la textura del suelo, el sistema radicular, la cobertura de materia orgánica y la actividad microbiana. El cambio paulatino en el uso del suelo desde pastos a plantación forestal, genera ventajas para la protección del recurso hídrico. Disminuye la erosión y contaminación de ríos y atenua la intensidad de los eventos de escorrentía. 
Existe la posibilidad de que las subcuencas del Río Virilla y del Río Durazno funcionen como áreas de recarga para acuíferos someros y profundos. La recarga estaría ocurriendo por medio de los lechos de los ríos, en los cuales se encuentran expuestos materiales lávicos fracturados. Un manejo adecuado del uso del suelo y un desarrollo urbano sostenible permitiría un aporte de agua de buena calidad a los ríos y quebradas.

Los balances hídricos de suelos son herramientas fundamentales para estimar de manera cuantitativa las implicaciones de un cambio en el uso del suelo.

La cuenca alta del Río Virilla es una fuente del recurso hídrico muy importante que debe ser protegida. Por un lado un número importante de habitantes se abastecen de captaciones de aguas subterráneas y superficiales dentro y fuera del área de estudio y por otro lado varias instituciones lo utilizan para la generación de energía eléctrica. El desarrollo de las actividades potenciales aquí propuestas, deben integrar la participación de los propietarios de tierras, los consejos municipales, el PLAMA VIRILLA y la comunidad local. La labor de cada sector permitirá la complementación de manera efectiva en pro de la protección del recurso hídrico en particular y del ambiente en general.

\section{AGRADECIMIENTO}

Se agradece la colaboración del Ing. Gunther Schozinsky en las críticas planteadas al manuscrito y mejoramiento del mismo.

\section{BIBLIOGRAFIA}

GÓMEZ, P.L., 1985: Vegetación y clima de Costa Rica. - 2 Vol. EUNED. 21 mapas. San José.

LIRIOS, J.F., 1980: Manual de estudios hidrológicos. - ONU, OMN. No 70. 200 págs. Cartago.

LOSILLA, P. M., ARIAS, M.G., CERVANTES, U.S., GÓMEZ, L.J., 1992: Estudio biófísico y socio-económico del sector del Cerro Guararí. - FUNDECOR. 20 págs. Heredia.

VARGAS, A., 1994: Evaluación de características químicas de aguas superficiales e hidrogeológicas en las subcuencas parte alta Río Virilla y Río Durazno, cantón Vázquez de Coronado, Provincia de San José, Costa Rica. - 239 págs. Escuela Centroamericana de Geología, Universidad de Costa Rica (tésis inédita). 